\title{
When does the personal vote matter for party loyalty? The conditional effects of candidate-centred electoral systems.
}

\author{
July 30, 2019
}

\begin{abstract}
When do candidate-centred electoral systems produce undisciplined parties? In this paper we examine party discipline under open list proportional representation, a system associated with MPs cultivating personal constituencies. We present a model explaining how legislators' preferences and support among voters mediate political leaders' ability to enforce discipline. We show that disloyalty in candidate-centred systems depends on parties' costs for enforcing discipline, but only conditional on MP preferences. MPs who share policy preferences of their leaders will be loyal even when the leaders cannot discipline them. To test the model's implications, we use data on legislative voting in Poland's parliament. Our empirical findings confirm that disloyalty is conditioned on party leaders' enforcement capacity and MP preferences. We find that legislators who contribute more to the party electorally in terms of votes are more disloyal, but only if their preferences diverge from the leadership. Our results suggest that the relationship between open lists and party disloyalty is conditional on the context of the party system.
\end{abstract}

keywords: electoral systems, legislative voting; parliaments; party voting unity; personal vote; political parties. 


\section{Introduction}

Scholars of comparative politics have long focused on the role of the electoral system in mediating how legislators respond to the competing pressures of party and constituency. Comparative work on party list systems has emphasised the role of incentives for intraparty competition (Gallagher and Marsh, 1987; Marsh, 1985). The personal vote is especially associated with the candidate-centred "open list" proportional representation (OLPR), where individual candidates receive votes and only vote shares determines whether candidates win seats. ${ }^{1}$ While candidates of the same party pool their votes on the same list, OLPR creates incentives for candidates to compete with co-partisans. Because of the importance of votes for individual candidates, open lists are thought to motivate candidates to cultivate a personal vote (Carey and Shugart, 1995; Ames, 1995) - a reputation distinct from co-partisans. In the legislative arena, if roll call voting influences individual reputations, we would expect incentives for MPs to vote in accordance with constituent demands, even against their party's collective position (Carey, 2009)

Because voters determine the priority with which candidates on a list are awarded seats in the legislature, the presence of such individualising incentives in the electoral context should translate into greater difficulty in enforcing party discipline. Yet, especially in parliamentary regimes, the pressure to vote with party leaders is persistently high (Bowler et al., 1999; Laver and Shepsle, 1999). Perhaps unsurprisingly, then, evidence for a relationship between open-list PR and lower party voting unity has been mixed (Bowler and Farrell, 1993; Carey, 2009; Hix, 2004; Depauw and Martin, 2009; Desposato, 2006; Coman, 2015). Sieberer (2006) finds, for example, that open list systems in Finland and Denmark represent, respectively, the lowest and highest party voting unity observed in a sample of Western Europe.

While there is ample evidence that open-lists are important to the electoral and party

\footnotetext{
${ }^{1}$ As we discuss below, the mechanics we describe for OLPR are also present in "flexible list" systems as well. In such systems, voters can influence a party list's rank order via preferential votes only if candidates receive a certain quota of votes. Our arguments below apply to any list system with individual candidate votes, so long as these votes are sufficient to resist party pressures.
} 
politics in general (Shugart, Valdini and Suominen, 2005; Golden and Picci, 2008; Ames, 2001), how this matters for party voting unity is less clear. ${ }^{2}$ Here we suggest that, while OLPR indeed makes party discipline more difficult to achieve, disloyal behaviour will be systematically observed only under certain conditions. Specifically, we argue that when an MP's personal vote is a significant contributor to the party's electoral success the party leadership is inclined to tolerate disloyalty. However, whether or not an MP will try to take advantage of his personal vote in this way is depends on the extent to which the MP has policy disagreements with the party leadership. In other words, open lists should reduce party voting unity only when there is preference divergence between an MP and the leader and that MP is capable of attracting a sizeable amount of votes in the electoral district.

We formalise this dynamic with a model accounting simultaneously for party resources, party preference cohesion, and MPs' electoral strength. As Borz and Janda (2018) note, terms relating to party unity and cohesion are used variably in the literature. By party preference cohesion we refer to the extent to which preferences of individual members are aligned with the leadership, which in turn derives from the heterogeneity of preferences among members. The latter concept is equivalent to what Borz (2009) calls "ideological cohesion." 3

With our model, we describe in particular 1.) how individual loyalty responds in equilibrium to changes in the leader's power to enforce discipline and 2.) how the degree of discipline each member requires for loyalty depends on both her electoral clout and the extent to which her preferences diverge from those of the leadership. Because of the complexity of interactions resulting from these factors, we derive expectations about the conditional effects of preferences and electoral clout on loyalty, while also accounting for varying levels of party resources. By making the assumptions and predictions precise, we shed light on how

\footnotetext{
${ }^{2}$ By "party voting unity", we mean the extent to which members of a party vote together in the legislature (Carey, 2007), while "disloyalty" refers to individual legislators voting against their party's position (Mainwaring and Perez-Linan, 1997)

${ }^{3}$ Borz (2009) distinguishes between several different concepts of cohesion, including voting cohesion, which we call "party voting unity" above.
} 
and when party leaders can counteract the pressures from voters on the party's rank and file membership. By separating the effects of institutional incentives from those related to party discipline, the model helps explain the wide variation in party voting unity observed among candidate-centred electoral systems.

The model explicitly incorporates two aspects of party organisation: (1) the party leadership's ability to enforce discipline and (2) the party's ability to reward loyalty. Consequently, our model offers insights pertinent to the relationship between party centralisation, party preference cohesion, and the personal vote (Ceron, 2013, 2016; Borz and de Miguel, 2017). Ceron (2013) has posited and empirically demonstrated, for instance, that disloyalty "is conditional on how powerful the whipping resources available to the leadership are."[p248]. Similarly, Ceron (2016) shows that the impact of factional conflict can be counteracted "when the party leader is autonomous and can rely on powerful whipping resources to impose discipline." As we explain below, our model elaborates the microfoundations of these ideas, showing that personal vote incentives affect members differentially, with the effect on party loyalty depending on the leverage of individual legislators vis-a-vis the party leadership.

We test the model's empirical implications using recorded voting data from Poland's Sejm, a parliament elected with an open-list electoral system, where all roll call votes are recorded, and where patterns of bill sponsorship provide a measure of preferences independent of roll call behaviour.

In our empirical analysis, we find that party loyalty corresponds to the electoral leverage of the individual MP, which, we argue, determines the leadership's ability to enforce discipline. Further, we find that the effect of MP vote shares on disloyalty is strongest for MPs that appear to diverge the most from the preferences of their party leaders, which we measure using patterns of bill cosponsorship outside of their party. We interpret our findings to suggest that while open-list PR indeed creates significant counter pressures for party voting unity, we will not observe disloyalty under most circumstances. Disloyalty among MPs with preferences that diverge sufficiently from the leadership will be observed only when they pos- 
sess sufficient clout. However, even when MPs are loyal to their party, the presence of OLPR always "matters" in the sense that its personal vote features always play a consequential role in how discipline is achieved.

\section{Open lists and party discipline}

Among proportional representation electoral systems, personal vote incentives are strongest in open lists (OLPR). In OLPR, voters can vote for a specific candidate within their preferred party. The votes for candidates within each party list are used to determine the priority with which candidates will obtain seats in the assembly. In contrast, in closed list proportional systems (CLPR), voters are limited to a party vote and party leaders determine the rank by which candidates are awarded seats. This power contributes greatly to party leaders' capacity to enforce party discipline (Carey, 2007, 2009).

Open lists are in regimes as diverse as Brazil, Latvia, Finland, Denmark, and (formerly) Italy. Additionally, a number of other countries blend elements of OLPR into their electoral systems. In flexible list systems, ${ }^{4}$ the position of the candidate on the list determines the priority of entering the legislature only if the vote share of the candidate falls below a threshold. ${ }^{5}$ The same dynamics for disloyalty that are present in OLPR systems may also emerge in flexible list systems but will be conditioned on members' ability to clear the threshold. ${ }^{6}$ The OLPR context allows us to focus on the general tendencies arising from preference votes.

The notion that OLPR creates incentives for candidates to compete with co-partisans is suggested by an array of research (e.g. Golden and Chang 2001; Ames 1995; Traber,

\footnotetext{
${ }^{4}$ Including the Czech Republic, the Netherlands, Belgium, Austria, Sweden, Iceland, Bulgaria (before 2007), Slovakia, Indonesia, Slovenia, and Peru (Renwick and Pilet, 2016)

${ }^{5}$ These vary considerably; for example, from $20 \%$ (Czech Republic) to $50 \%$ of the individual vote quota (The Netherlands)

${ }^{6}$ Carroll and Nalepa (2019) formalise the spectrum of flexible lists (from open to closed-lists) as the difference between two electoral thresholds set by the party leader to win a seat in the legislature: a lower threshold for loyal party members and a higher threshold for disloyal members. The greater the difference, the more power the party leader has to ensure the members are loyal. Based on this parametrisation, we conjecture that the results in this paper carry over to flexible lists, moderated by these thresholds.
} 
Hug and Sciarini 2014). This competition for individual votes implies that MPs should vote in accordance with constituent demands, even against their party Carey (2007). Without divergence between a legislator's preferences and the party, we should not observe disloyalty to the party even without party pressures (Krehbiel, 1993).

When members' preferences are in conflict with their parties, leaders may still use their resources to enforce discipline. Parties may provide rewards to loyal members (Martin, 2012; Fujimura, 2012) or may sanction disloyalty by, for instance, suspending membership or threatening nominations (Benedetto and Hix, 2007; Andeweg and Thomassen, 2011; Bowler et al., 1999; Gallagher, 1998).

However, whether the threat of losing a nomination is credible depends on how much electoral leverage the individual member enjoys. A popular member running on a party list in OLPR not only secures a seat for herself in the legislature but also contributes her electoral support to the party as a whole, helping elect less popular members. Hence, punishing popular members by denying a place on the list can be counter-productive for the party's electoral goals.

In OLPR systems, a candidate's share of votes secured in the district can serve as an objective measure of that candidate's electoral value to a party. With this electoral 'clout', MPs are not as easily disciplined into voting with their party. Consider as an example an MP elected under open lists in the Polish Sejm who typically "wins an overwhelming majority of votes from [his] district" and thus has "never felt conflicted between party interests and voter interests" therefore "always follows his voters" (Mojzeszowicz, interview 2010). That is, the leverage his popularity afforded him vis a vis the party leadership left him relatively free of party discipline. Compared to other electoral systems, OLPR makes formal and clear the means of obtaining this 'clout.'

In sum, loyalty is first mediated by the policy preferences of members. Second, it is mediated by the sanctions and rewards available to party leaders to pressure members to vote with the party. Third, it is mediated by members' electoral leverage to avoid such 
pressure.

The model below allows us to formulate predictions about how preferences interact with MP clout. From our model, we find that party loyalty is partly determined by the MP-level variation in the leverage the individual MP derives from a personal vote, which, we argue, determines the leadership's ability to enforce discipline. Further, we find that the effect of the personal vote on disloyalty is strongest for MPs that appear to diverge from the preferences of their party leaders, measured as their tendency to engage in bill cosponsorship outside of their party. With regard to party resources available to reward members, although higher resources make enforcing discipline easier, there is no moderating effect on the leverage derived from the personal vote. In other words, resources used for rewarding discipline have the same effect on MPs with a lot of voter support as they do on MPs with low voter support.

\section{The Model}

The model presented in this section captures the interaction between a party leader and a party member. For present purposes, however, the MPs disagreements with leaders' preferences may be due to any combination of their individual views, pressure from constituents, ${ }^{7}$ interest groups or personal networks. Hence, to be as general as possible, we abstract from the possible reasons that the MPs preferences diverge from those of the leadership and subscript the leader's ideal point "MP."

We define $N=\{L, M P\}$ as the set of players.

Our model begins with a party leader charged with implementing a party policy, which may arise from different forms of decision making processes. ${ }^{8}$ The game starts with a move of $L$, who applies discipline to one of two policies 0 and $x$ from a one-dimensional policy space. ${ }^{9}$

\footnotetext{
${ }^{7}$ Although voters are not formally players in the game, we can interpret the preferences of the MP as potentially representing them, with the distance between the ideal point of the leader and the member representing the dual accountability problem facing MPs in OLPR systems (Carey, 2007).

${ }^{8}$ This includes, for example, a decentralised process involving influence from factions (Ceron, 2016).

${ }^{9}$ By "applies discipline" we mean that the leader chooses one of two policies with an indication that he expects members to support the party position. This expectation can be more or less explicit in practice.
} 
In the case of a governing party, one may think of $x$ as a policy that has been proposed by the cabinet and 0 as the status quo. In the next stage, the MP chooses whether to follow discipline, interpreted in the game as voting with the Leader. If the MP complies, the game ends. In the event of non-compliance, in the following stage, the Leader decides whether to enforce discipline. ${ }^{10}$

"Enforcing discipline" refers to actually issuing a sanction for violating the leader's directive. Empirically, sanctions range from monetary penalties to suspension in caucus membership rights. The most effective sanction, however, is failing to nominate a candidate for the party list in the next election cycle. This is precisely what justifies the payoff to the leader associated with enforcing discipline. It is costlier to discipline high-clout members than low-clout members. Following the Leader's decision about enforcing discipline, the game ends. In short, being loyal is synonymous in our model with following discipline, that is, with the MPs choosing the same policy as the Leader; being disloyal is synonymous with violating discipline, that is, with choosing the opposite policy as the leader; and enforcing discipline is synonymous with the Leader choosing the action "discipline" in the last stage of the game.

Formally, the Leader's strategy space is $S_{L}=\left\{A_{L}^{1} \times A_{L}^{2}\right\}$, where $A_{L}^{1}=\{0, x\}, A_{L}^{2}=$ $\left\{f: A_{L}^{1} \times A_{M P} \rightarrow\{0,1\}\right\}$, and 1 represents the decision to enforce discipline and 0 represents the decision to refrain from enforcing discipline. The MP's strategy space is $S_{M P}=$ $\left\{f: A_{L}^{1} \rightarrow\{0, x\}\right\}$. The Leader's and MP's ideal points are represented by $b_{L}$ and $b_{M P}$, respectively, in a one-dimensional policy space. The utility of the Leader is shaped by his policy preferences and the cost of enforcing discipline, the last of which depends on the MP's clout, represented by $\pi \epsilon[-1,1]$. Hence: $U_{L}\left(s_{L}, s_{M P}\right)=-\left(b_{L}-a_{M P}^{1}\right)^{2}-\pi V(d)$. MPs with $\pi$ close to 1 are more likely to win a seat in the legislature irrespective of how well their party does in the election as a whole. MPs with $\pi$ close to -1 depend heavily on the popularity

\footnotetext{
${ }^{10}$ Note that our approach shares features with the most influential work on this topic by Kam (2009), who focuses on party discipline in Westminster systems. Among the important differences is that, in Westminster systems party leaders are positioned to propose policies. We, however, envision a multiparty context where leaders would not always have this power.
} 
of others in their party for retaining their parliamentary seats. The high $\pi$ MPs are those colloquially referred to in Poland as the "steam engines," because they attract many voters to a party and enable the election of weaker (low $\pi$ ) candidates. In the subsequent discussion we refer to MPs with $\pi>0$ as "high clout" and to MPs with $\pi<0$ as "low clout". To be clear, there is a continuum between low and high clout types. Because high clout MPs supply a considerable part of the party's vote share from a given list, they are considerably more independent in the legislature than MPs, who owe their seats to the party.

$V(d)$ represents the value of enforcing discipline that are internalised by the party leadership. In the case of a high clout type, this effect is transformed into a cost by the coefficient $\pi$, but in the case of a low clout MP, it is transformed into a benefit. The ease with which leaders can enforce discipline depends not only on the MP's clout but also on some party-level characteristics. The parameter $d$ can be thought of as capturing part of party centralisation. Centralised parties will find it easier to sanction members who violate discipline compared to decentralised parties. Hence we can think of low values of $d$ as corresponding to decentralised parties and high values of $d$ as corresponding to highly centralised parties. Note, that the level of centralisation is independent of the ideological cohesion of the party-how distant from the leadership are the members' ideal points. It is also independent of the resources the party has at its disposal with which to reward loyal members. We assume that:

$$
d>0
$$

and

$$
V(d)= \begin{cases}d & \text { if } a_{L}^{2}=1 \\ 0 & \text { otherwise }\end{cases}
$$

The utility of the MP, on the other hand, reflects his concern for the voters, avoiding punishment for breaking discipline, weighted by his vote share, and the party resources he receives for supporting the leadership. Hence: $U_{M P}\left(s_{L}, s_{M P}\right)=-\left(b_{M P}-a_{M P}^{1}\right)^{2}+v(r)+V(d) \pi$ where $v(r)$, is a function transforming the resources the leadership can offer the MP if he supports the leadership's decisions: 


$$
r>0
$$

and

$$
v(r)=\left\{\begin{array}{lc}
r \quad \text { if } a_{L}^{1}=a_{M P}^{1} \\
0 \quad \text { otherwise }
\end{array}\right.
$$

High levels of $r$ characterise members of parties that expect to have access to spoils of office. Lower levels of $r$ describe members of parties lacking access to power. Such members have less to lose from disagreeing with the leadership on policy choice whether this entails breaking party discipline.

In our model, the voters are not a strategic player but the ideal point of the MP could be interpreted as constituency pressure to deviate from the party leadership's position. More broadly, we can interpret $b_{M P}$ as shaped by any parameter that enters the MP's decisionmaking process as long as it is separate from party influence, such as the preferences of interests or political networks of the MP.

The game above is one of complete information and we solve it for Subgame Perfect Nash equilibrium in the appendix.

\section{Interpretation}

To make empirical predictions, it is useful to present the results as equilibrium outcomes. Figure 1 does so as a function of the MP's ideal point, $b_{M P}$ relative to the two exogenously given policies 0 and $x$, captured by the location of $\frac{x}{2}$, and MP vote share, $\pi$. To interpret the results in a more approachable way, we refer to the representation of parameter values for high clout MPs in Figure 1 as "Regions" and to the representation of parameter values for low clout MPs as "Areas."

\section{-Figure 1 about here-}

Recall our assumption that the leader's ideal point is to the right of the MP's. Fixing $b_{M P}<b_{L}$ simply implies that indifferent or undecided MPs will always support the same 
policies as the leader so their preferences are convergent with the leader. This assumption introduces no loss of generality.

What counts as indifference sufficient to share the leader's preferences is falling within $\frac{r}{2 x}$ of $\frac{x}{2}$, the midpoint between 0 and $x$. In the case of the most indifferent (or undecided) MPs there is no difference between the behaviour of high clout and low clout MPs. The model makes exactly the same predictions for parameters in Region B as for parameters in Area 3.

Note that indifference between the considered policies, as interpreted here, does not mean that the MP's ideal point is exactly $\frac{x}{2}$, but that it falls within a distance from that point. That distance depends on the parameter $r$ representing the resources parties have at their disposal to reward loyalty. Members of parties with sizable resources will support leadership more readily than members of parties with fewer resources.

Outside of the indifference region, our results immediately indicate that low clout MPs will not vote with the leadership under the same circumstances as high clout MPs.

If the high clout MP has preferences that are beyond Region B (e.g. in Region A) he will do whatever his constituents prefer: he will support 0 if their ideal point is in Region A (that is, to the left of $\frac{x}{2}-\frac{r}{2 x}$ ) and he will support $x$ if his constituents' ideal point is to the right of $\frac{x}{2}-\frac{r}{2 x}$. In equilibrium, the high clout MP is never disciplined.

In Area 3, the low clout MP does not require discipline to vote with the leadership. Extending away from Area 3 is a shaded triangular region (Area 2) where the leadership has a credible threat of imposing discipline. This credible threat induces the MP to back the leadership's choice, because disloyalty would result in sanctions. The region of credible threat to discipline increases as the MP's vote share declines, suggesting that MPs with the lowest clout are most vulnerable to discipline. Area 2's base is widest for the most negative values of $\pi$. Note, that an increase in $d$, the parameter representing party organisation and capacity for disciplining action (which can be thought of as centralisation), is also associated with the wider base of Area 2, where discipline keeps the low clout MP in line. This implies, all else equal, that better organised parties find it easier to maintain unity when their membership 
lacks ideological cohesion. Of course, this comparative static holds only for the low clout case. Even a very well organised party cannot constrain high clout MPs with divergent preferences. Finally, in the case of constituency preferences corresponding to Area 1, low clout MPs will act in accordance with their own policy preferences. They will be disciplined, but given the extreme preferences of this electorate, they prefer to accept sanctions rather than punishment from voters.

The main empirical implication for MP loyalty is that, for policy preferences and MP vote share corresponding to Area 2, the shaded triangle in Figure 1, low clout MPs will be more loyal than high clout with the same preferences. Consequently, parties with more high than low clout MPs will be less unified than parties with more low relative to high clout MPs. The conditional effect of vote share on preferences implies that even MPs with extreme policy preferences can be subjected to pressure from the leadership if their clout is sufficiently low. The second empirical implication is that resource-rich and better-organised parties enlarge the area in which MPs and leaders act in concert, whereas parties that are poorly organised have very narrow areas of MP support for leadership. Resources correspond to the value of party membership to a member. For instance, parties controlling the cabinet would be higher in resources than parties that are relegated to the opposition (Carey, 2009). In contrast, party organisation represents the extent to which disciplining members is a matter of party routines within the parliament.

Note, that although an increase in resources, $r$, increases the area where MPs vote together with the leadership, it affects high and low clout MPs in the same way; that is, there is no conditional effect of vote share associated with resources. This is not so, however, with $d$, the parameter that operationalises a party's organisational capabilities. Better organised parties can exert more pressure on MPs with low vote share than on MPs with high vote share by making them toe the line where their preferences would urge them to do otherwise. ${ }^{11}$

\footnotetext{
${ }^{11}$ We lack the data to operationalise the distance between the two policy proposals in the empirical analysis below. Note, however, that the closer policy $x$ is from 0 , which can be interpreted as the status quo, the greater the region where the leadership can secure loyalty, as the central region in Figure 1 decreases in $x$. This empirical implication allows us to predict what would happen if the choice of policy $x$ were not
} 
As remarked above, a party's centralisation can affect its ability to enforce discipline and degrees of centralisation can map onto the parameters of our model. Decentralised parties would have their value of parameter $d$ set close to 0 , such that the decision of the leader in the final stage of the game would have very little consequence for his payoff and the difference between enforcing discipline on the high and low clout member, respectively, would be miniscule. This would therefore reduce to a decision problem for the party member, choosing whichever policy he prefers subject to expectations of rewards with resources $(r)$. Critically, the solution to this decision problem would in no way hinge on the clout of the party member. ${ }^{12}$

\section{Empirical Implications}

A clear implication of the model above is that observed disloyalty will be largely a function of the costs of enforcing discipline. Recall that those MPs who are major contributors of votes to the party - the "high clout" types - are the most costly MPs on which to enforce discipline, since their sizeable contribution to the party makes the most severe punishment (denying nomination to the list) impractical for party leaders. In the case of one popular MP in Poland, for instance, "his name recognition... was so effective that not only did the six candidates who were expected to win seats in the Torun district enter the Sejm, but also a seventh person managed to secure a seat" (Ardanowski, interview 2010). As the model demonstrates, the leader's ability to enforce discipline on members with such clout is weak compared to others with less personal following. Imposing discipline upon major vote-getters is more costly than on others. In the Polish case, a former Vice Speaker notes that "the President asked fifteen MPs to vote in a way that would violate party discipline."

exogenous, but chosen by the leadership. A leader maximising party voting unity as demonstrated in the voting record would set the agenda with policies that are close to the status quo.

${ }^{12}$ As we suggest above, decentralised parties may have less control over resources to distribute to their members, because they may need to negotiate the distribution of these resources with other factions of the party. In this case, not only $d$ would be close to 0 , but so would $r$. The model with such parameter values would reduce to a decision problem of the party member who would simply choose the policy that it closest to his ideal point. This result would not hinge on the member's clout either. 
Whereas normally "disobedience would result in having one's name removed from the list, among the fifteen, there were about seven who were so-called 'steam engines' and removing them would result in losing considerable votes" (Wenderlich, interview 2011). By contrast, an MP without this electoral clout will have much less ability to vote against the party. One such MP in Poland notes that, "in a vote to appoint constitutional court justices, the party urged its members to vote against my law school advisor. I asked the caucus whip for an exemption. It was denied even though it would not have changed the final outcome" (Karpinski 2009).

The empirical implication is that members on whom enforcing discipline is more costly should exhibit less loyalty. This can be captured by a continuous concept - an MP's vote share. Therefore, observed party loyalty should be lower for MP's with the largest vote shares, on average. However, whether enforcement (or lack thereof) will play a decisive role in loyalty depends on the preferences of the MPs to oppose party policy positions. Members who most closely share the preferences of leaders should tend to be loyal even when enforcement capacity is relatively low. Meanwhile, members who prefer to pursue policies that satisfy constituencies diverging from their party should be disloyal insofar as party discipline cannot be easily enforced. We therefore expect that the effect of enforcement power on MP loyalty should be stronger for MPs whose underlying policy preferences appear to be most different from those of their party leadership. That is, the degree to which MPs will become more disloyal as a result of higher vote shares is conditional on whether their preferences diverge from that of the party leadership.

\section{Empirical Analysis}

For our empirical analysis, we use data from the Polish Sejm, a parliament elected under open list PR that provides us with a substantial amount of available electoral and legislative data suitable to answer the questions raised above. Poland's open list electoral system clearly 
demonstrates what MPs describe as competition "essentially going on between people on the same list. Instead of cooperation in competing against opponents from different lists, they fight each other, competing for media attention, name recognition and even volunteers" (Karpinski interview 2010). The Polish case has also been associated with relatively weak party organisations and loyalty (Gwiazda, 2009; Millard, 2008), and thus provides useful variation for our study.

We use the cross-sectional variation in party loyalty scores to examine the implications described above. Subsequently, we examine party-level unity scores across votes over time, focusing on the electoral context facing the party as a whole. We use roll call data from 1997-2005, which covers all votes from the 3rd and 4th terms of the Polish Sejm. ${ }^{13}$ During these terms, all roll call votes were recorded and all votes are used in the calculation of these measures.

We measure the degree of party loyalty using for each MP the measure of "absolute" party loyalty proposed by Mainwaring and Perez-Linan (1997), which counts abstentions as votes against the party. This score, which ranges from 0 to 100, simply represents the percentage of votes on which an MP voted for or against with the party's overall position, including cases of abstention as disloyal. ${ }^{14}$ The party's position is based on the voting direction of a majority of the party. ${ }^{15}$

As described above, party leaders' enforcement depends on their ability to impose costs for disloyalty on an individual MP. In general, the leadership makes use of the nomination

\footnotetext{
${ }^{13}$ The Sejm since 1997 has been recording and making public all the votes cast in the Chamber.

${ }^{14}$ Interviews with sources in the Polish Sejm and analysis of archival materials suggests that abstentions were the most common form of disloyalty against the party, due to harsh formal penalties for explicitly voting against the party (including fines and expulsion from the party caucus). Still, while it was typical for MPs to avoid votes, their presence for voting sessions was officially obligatory, with numerous reminders issued by the caucus whips and possibly sanctions. Thus abstentions were costly enough not to occur without reason, but are frequent enough to function as the main form of party disloyalty.

${ }^{15} \mathrm{MPs}$ who are independents (not members of any party) are excluded from the sample as are those members that switch parties during the term from the party list on which they were initially elected. MPs who leave their party would not have the dynamic we model above in which their importance in the next election constrains the party leaders. Moreover, their behaviour in terms of voting and bill submission is not comparable to other members, as it is limited only to a portion of the term. MPs from small parties with less than 15 members are excluded in order to maintain comparability
} 
sanction mechanism described above. ${ }^{16}$ But, due to differences in contributions to the party, reflecting popularity with voters, some members are less dependent on the party than others. In Poland's open list context, this role is clearly recognised, as one MP notes: "the conventional wisdom is that this person is the 'steam engine' who attracts so many votes that he will not only secure a seat for himself in the legislature, but will also bring along a number of other MPs..." Since clout is a continuous concept tied to contributions, we operationalise this leverage as the vote shares members contribute to the party list. Those with the greatest vote shares, according to the argument above, should be most successful at evading party discipline and thus we would expect to find them to be less loyal on average. The quantity we employ to capture this variation is the vote share - the percentage of votes a given MP received in his or her district.

\section{- Table 1 about here-}

In Table 1, we show the results of an OLS regression of loyalty scores on vote share (Vote Share), membership in a party in the governing coalition (Govt Party), and the size of the party, with fixed effects for the term and party-level random intercepts.

First, we examine a basic model that establishes a baseline relationship with our measure of electoral clout. Here, we find that members responsible for larger vote share are indeed somewhat less loyal on average, consistent with the notion that discipline is less likely to be imposed as MPs attain high clout status. Also, we find that the larger parties are, on average, more loyal, regardless of government status.

In a second model, we introduce an operationalisation of MP preferences. Recall from above that although MPs with high vote shares should be less subject to discipline on average, this should be true primarily for MPs whose preferences diverge from the leader's. Specifically, only under circumstances where there is some disagreement between MPs and party leaders should we expect a strong relationship between vote share and loyalty. In

\footnotetext{
${ }^{16}$ As one Polish MP commented, "It's an important instrument of control to offer someone a spot on the list and assign them to a district" (Jaruga-Nowacka, interview 2009).
} 
a second model, we examine a closer approximation to the prediction made above: when enforcement is at its weakest, that is for high clout MPs, those with preferences further from the party leaders will be less loyal. Naturally, it is not possible for our purposes to use measures of preferences that derive from voting (Borz and Janda, 2018) and these are generally inappropriate in parliamentary regimes (Carroll and Poole, 2014). Instead, we take advantage of another data source with political content - the cosponsorship of legislation. Importantly, this behaviour was not regulated by parties during the time under study. We use the bill cosponsorship decisions of members to assess whether an MP appears to have preferences that diverge from that of their leaders, or perhaps wants to signal these differences to voters (Crisp, Kanthak and Leijonhufvud, 2004). To capture this, we construct a measure of the tendency for members to cooperate on legislation sponsored by other parties. In the Polish Sejm, all legislation initiated as a private bill must be cosponsored by at least 15 MPs and these bills constitute a sizeable proportion of those submitted (40\% in the 3rd [1997-2001] term and 25\% in the 4th [2001-2005]). They also constitute 40 (in the 3rd term) and $50 \%$ (in the fourth term) of bills that were actually passed. Thus, almost all members over the course of these terms cosponsored a bill and consequently can have an outside-party cosponsorship score assigned. During this time, party rules restricting cosponsorship had not yet been implemented, leaving us with an informative behaviour reflecting individual MP decisions. ${ }^{17}$ We consider MPs to have indicated divergent preferences from their party leaders when they co-sponsor proposals for which a majority of co-sponsors come from a different party. The reasoning behind this measure is that frequent sponsorship of legislation with MPs from other parties suggests an effort to pursue policies counter to those of one's own party leadership — or at least to cultivate a reputation for doing so (Crisp, Kanthak and Leijonhufvud, 2004; Alemán et al., 2009). Naturally, this proxy cannot be said to account for all aspects of members' disagreements with their parties. Here we only assume that members most frequently cosponsoring outside their party are more likely, on average, to

\footnotetext{
${ }^{17}$ After the period under study, changes to party internal restrictions in sponsorship behaviour make later data inappropriate to serve as a proxy for individual MP preferences.
} 
have disagreements. In this second model, we include a term interacting vote share with Outside-Party Cosponsorship, which is a log transformation of the proportion of legislation an MP cosponsors for which most sponsors are from outside the MP's party. Naturally, this measure cannot capture all aspects of preference divergence with an MP's party, but identifies MPs that appear to be more likely hold such views.

These results suggest that across our sample, MPs with more outside-party cosponsorship of legislation have a much stronger relationship between their vote share and their observed disloyalty. In other words, members with significant electoral clout from their personal vote tend to vote more disloyally only when ideologically distinct from their party.

\section{-Figure 2 about here-}

To better understand these effects substantively, Figure 2 plots the effect of vote share across the range of outside-party cosponsorship using results from the interaction model. The graph shows that there is no statistically significant relationship between vote share and loyalty for an MP with no outside-party cosponsorship. This type of MP may have the clout to avoid discipline, but likely faces few situations where voting against the party is desirable even in the absence of discipline. However, for an MP with apparently divergent preferences (high outside-party cosponsorship activity), the effect is substantively much stronger. We interpret this as consistent with our expectation above that party discipline is dependent on parties' ability to enforce it and is conditional on MPs having preferences ideologically divergent from the party leadership.

\section{Discussion}

Scholars have long investigated how parties reconcile the personal vote incentives of their members with their own goals of legislative unity. The OLPR electoral system results in personal votes that make clear the proportion of votes the member secures in her district. 
Since they cannot lose their nomination without harming party performance, we may expect less discipline and greater disloyalty on average.

However, following Krehbiel (1993), we note that disloyalty is conditional on whether a legislator's preferences also diverge from those of the party. When a legislator's preferences coincide with the policy supported by the leadership, enforcing party discipline will not affect voting behaviour. When preferences do diverge, parties can counter the pressures facing legislators, depending on their organisational capacity.

Our model of discipline under open lists allows us to make clear predictions about the exact circumstances where disloyalty will be observed. Although disloyalty is a function of vote share, this is conditional on preferences diverging from the party. An MP with electoral clout is necessary but not sufficient for observing disloyalty. We then evaluate what party leaders can do to obtain MPs' support for party positions, despite personal-vote-seeking incentives. When parties use rewards to induce loyalty, these resources have the same effect on low and high clout members. Finally, our model underscores the importance of party organisations' institutionalisation. To the extent that there has been a routinisation of party procedures, parties have an easier time enforcing discipline.

We test this model in a setting with especially suitable electoral and party characteristics. Poland uses OLPR and records all parliamentary votes, allowing us to measure electoral clout and party loyalty. During the time under study, cross-party cosponsorship patterns in Poland allow us an intuitive measure of preference divergence, separate from voting behaviour. In addition, Poland's parties, at an intermediate stage of institutionalisation, had not yet clearly sorted into cohesive ideologically cohesive parties. This creates variation helpful for the conditional effects in our analysis, compared to established advanced democracies.

Overall, we find that MPs who win more votes in their districts are less loyal to their parties, but most importantly that members with the most divergent underlying preferences from their party (captured by sponsorship activity with other parties) are most disloyal when their vote share would allow them to best avoid enforcement of discipline. 
Our findings are consistent with an important mediating role of institutions. While MPs are often concerned with their personal reputations, the factors we highlight can explain why party disunity has often not been observed. We conclude that a large range of variation in voting unity depends on the nature of party organisations and its enforcement capacity. This provides an explanation for why personal voting in many advanced democracies - especially in flexible list systems - has not produced party voting disunity. In most situations, parties can counteract the personal vote effect of OLPR if they are organisationally capable of enforcing discipline. While open-list PR can indeed create significant counter pressures for party voting unity, these would likely manifest themselves as party disunity more commonly in less-institutionalised party systems, where recruitment processes allow more diverse parties and where the electorate is more responsive to the individual reputations of candidates. Parties have strong incentives to avoid the combination of individual electoral clout and preference disagreement apparent during the period of the Polish Sejm under study. Yet, we also emphasise that even when MPs are loyal to their party, OLPR still matters in the sense that the personal vote always plays an important role in how discipline is achieved.

Our formal and empirical analysis provides insight into the wide variation in voting unity in the context of personal vote incentives. Although open-list PR provides voters with an opportunity to hold their representatives individually accountable, this opportunity is not in itself sufficient to produce MPs with behaviour that diverges from their party leaders. Instead, institutionalised parties are likely to be able to counteract the influence of the personal vote on party loyalty. Parties have strong incentives to avoid the combination of individual electoral clout and preference disagreement apparent during the period of the Polish Sejm under study.

In summary, the personal vote incentives of OLPR are persistently important for legislative voting because the nature of discipline is shaped by the leverage provided to MPs under the electoral system, as well as by the incentives parties have faced to recruit a diverse membership. We believe these results contribute to explaining the wide variation in the 
apparent unity of parties in candidate-centred electoral systems. 


\section{References}

Alemán, Eduardo, Ernesto Calvo, Mark P. Jones and Noah Kaplan. 2009. "Comparing Cosponsorship and Roll-Call Ideal Points." Legislative Studies Quarterly 34(1):87-116.

Ames, Barry. 1995. "Electoral strategy under open-list proportional representation." American Journal of Political Science pp. 406-433.

Ames, Barry. 2001. The Deadlock of Democracy in Brazil: Interests, Identities, and Institutions in Comparative Politics.

Andeweg, Rudy B. and Jacques Thomassen. 2011. "Pathways to party unity: Sanctions, loyalty, homogeneity and division of labour in the Dutch parliament." Party Politics 17(5):655-672.

Benedetto, Giacomo and Simon Hix. 2007. "The Rejected, the Ejected, and the Dejected: Explaining Government Rebels in the 2001-2005 British House of Commons." Comparative Political Studies 40(7):755-781.

Borz, Gabriela. 2009. "Determinants of Party Unity in Europe: A comparative study of parliamentary parties in twenty-three countries." CEU Political Science Dissertation, Budapest: CEU, Budapest College.

Borz, Gabriela and Carolina de Miguel. 2017. "Organizational and Ideological strategies for nationalization: evidence from European parties." British Journal of Political Science pp. 1-28.

Borz, Gabriela and Kenneth Janda. 2018. "Contemporary trends in party organization: revisiting intra-party democracy." Party Politics p. 1354068818754605.

Bowler, S., D.M. Farrell, R.S. Katz and European Consortium for Political Research. 1999. Party discipline and parliamentary government. Ohio State University Press Columbus.

Bowler, Shaun and David M Farrell. 1993. "Legislator Shirking and Voter Monitoring: Impacts of European Parliament Electoral Systems upon Legislator-Voter Relationships." Journal of common market studies 31(1):pp. 45-70.

Carey, John M. 2007. "Competing principals, political institutions, and party unity in legislative voting." American Journal of Political Science 51(1):92-107.

Carey, John M. 2009. Legislative voting and accountability. Cambridge Univ Pr.

Carey, John and Matthew Soberg Shugart. 1995. "Incentives to Cultivate a Personal Vote: a Rank Ordering of Electoral Formulas." Electoral Studies 14(4):417-439.

Carroll, Royce and Keith Poole. 2014. Roll Call Analysis and the Study of Legislatures. In The Oxford Handbook of Legislative Studies, ed. Shane Martin, Thomas Saalfeld and Kaare Strøm. Oxford University Press. 
Carroll, Royce and Monika Nalepa. 2019. "The personal vote and party cohesion: Modeling the effects of electoral rules on intraparty politics." Journal of Theoretical Politics .

Ceron, Andrea. 2013. "Brave rebels stay home: Assessing the effect of intra-party ideological heterogeneity and party whip on roll-call votes." Party Politics .

Ceron, Andrea. 2016. "Inter-factional conflicts and government formation: Do party leaders sort out ideological heterogeneity?" Party Politics 22(6):797-808.

Coman, Emanuel Emil. 2015. "Institutions and Vote Unity in Parliaments: Evidence from 33 National Chambers." The Journal of Legislative Studies 21(3):360-389.

Crisp, B.F., K. Kanthak and J. Leijonhufvud. 2004. "The reputations legislators build: With whom should representatives collaborate?" American Political Science Review 98(4):703716.

Depauw, Sam and Shane Martin. 2009. Legislative party discipline and cohesion in comparative perspective. In Intra-party politics and coalition governments, ed. Daniela Giannetti and Kenneth Benoit. Vol. 103120.

Desposato, Scott W. 2006. "The Impact of Electoral Rules on Legislative Parties: Lessons from the Brazilian Senate and Chamber of Deputies." Journal of Politics 68(4):1018-1030.

Fujimura, Naofumi. 2012. "Electoral incentives, party discipline, and legislative organization: manipulating legislative committees to win elections and maintain party unity." European Political Science Review 4(2):147-175.

Gallagher, Michael. 1998. "The Political Impact of Electoral System Change in Japan and New Zealand, 1996." Party Politics 4(2):203-228.

Gallagher, Michael and Michael Marsh. 1987. Candidate selection in comparative perspective. Sage.

Golden, Miriam A. and Eric C. C. Chang. 2001. "Competitive Corruption: Factional Conflict and Political Malfeasance in Postwar Italian Christian Democracy." World Politics 53(4):588-622.

Golden, Miriam A. and Lucio Picci. 2008. "Pork-Barrel Politics in Postwar Italy, 1953-94." American Journal of Political Science 52(2):268-289.

Gwiazda, Anna. 2009. "Poland's Quasi-Institutionalized Party System: The Importance of Elites and Institutions." Perspectives on European Politics 102(02):350-376.

Hix, S. 2004. "Electoral institutions and legislative behavior." World politics 56(2):194-223.

Kam, Christopher, J. 2009. Party discipline and Parliamentary politics. Cambridge University Press.

Krehbiel, Keith. 1993. "Where's the Party?" British Journal of Political Science 23(2):pp. 235-266. 
Laver, M. and K. A. Shepsle. 1999. "How Political Parties Emerged from the Primeval Slime: Party Cohesion, Party Discipline, and the Formation of Governments." Party Discipline and Parliamentary Government pp. 23-48.

Mainwaring, Scott and Anibal Perez-Linan. 1997. "Party Discipline in the Brazilian Constitutional Congress." Legislative Studies Quarterly 22(4):453-483.

Marsh, Michael. 1985. "The voters decide?: Preferential voting in European list systems." European Journal of Political Research 13(4):365-378.

Martin, Shane. 2012. "Why electoral systems don't always matter: The impact of 'megaseats' on legislative behaviour in Ireland." Party Politics .

Millard, Frances. 2008. "Executive-Legislative Relations in Poland, 1991-2005: Institutional Relations in Transition." The Journal of Legislative Studies 14(4):367-393.

Renwick, Alan and Jean-Benoit Pilet. 2016. Faces on the Ballot: The Personalization of Electoral Systems in Europe. Oxford University Press.

Shugart, Matthew Søberg, Melody Ellis Valdini and Kati Suominen. 2005. "Looking for Locals: Voter Information Demands and Personal Vote-Earning Attributes of Legislators under Proportional Representation." American Journal of Political Science 49(2):437-449.

Sieberer, Urlrich. 2006. "Party Unity in Parliamentary Democracies: A Comparative Analysis." The Journal of Legislative Studies 12(02):150-178.

Traber, Denise, Simon Hug and Pascal Sciarini. 2014. "Party unity in the Swiss Parliament: the electoral connection." The Journal of Legislative Studies 20(2):193-215. 
Table 1: Party Loyalty Across MPs

\begin{tabular}{|c|c|c|}
\hline & $\begin{array}{l}(1) \\
\text { All }\end{array}$ & $\begin{array}{l}(2) \\
\text { All } \\
\end{array}$ \\
\hline Vote Share & $\begin{array}{c}-3.306^{*} \\
(1.734)\end{array}$ & $\begin{array}{l}3.028 \\
(2.988)\end{array}$ \\
\hline Outside Cosponsorship & & $\begin{array}{l}0.456^{* * *} \\
(0.096)\end{array}$ \\
\hline Vote Share X Outside Cosponsorship & & $\begin{array}{l}-3.050^{* * *} \\
(1.154)\end{array}$ \\
\hline Govt Party & $\begin{array}{l}-0.343 \\
(0.875)\end{array}$ & $\begin{array}{l}-0.444 \\
(0.865)\end{array}$ \\
\hline Party Size & $\begin{array}{l}0.023^{* * *} \\
(0.007)\end{array}$ & $\begin{array}{l}0.026^{* * *} \\
(0.007)\end{array}$ \\
\hline 4th Term & $\begin{array}{l}1.385^{*} \\
(0.818)\end{array}$ & $\begin{array}{l}1.608^{* *} \\
(0.810)\end{array}$ \\
\hline Constant & $\begin{array}{l}93.244^{* * *} \\
(0.919)\end{array}$ & $\begin{array}{l}91.789 \text { *** } \\
(0.958)\end{array}$ \\
\hline Observations & 848 & 848 \\
\hline Number of pid & 11 & 11 \\
\hline
\end{tabular}


Figure 1: Comparative Statics: Low Clout MPs and High Clout MPs

Figure 2: Effect of Vote Share on Party Loyalty, Conditioned on Outside-Party Sponsorship behaviour

\section{Appendix}

Recall that the game presented in section 2, Enforcing Discipline, $\langle N, S, U\rangle$, is defined by $N=$ $\{L, M P\} S_{L}=\left\{A_{L}^{1} \times A_{L}^{2}\right\}$, where $A_{L}^{1}=\{0, x\}, A_{L}^{2}=\left\{f: A_{L}^{1} \times A_{M P} \rightarrow\{0,1\} \times\{0,1\}\right\}$, and $S_{M P}=\left\{f: A_{L}^{1} \rightarrow\{0, x\}\right\}$ and $U_{L}\left(S_{L}, S_{M P}\right)=-\left(b_{L}-a_{M P}^{1}\right)^{2}-\pi V(d)$ $U_{M P}\left(S_{L}, S_{M P}\right)=-\left(b_{M P}-a_{M P}^{1}\right)^{2}+v(r)-V(d) \pi$.

We made the following assumptions about the parameters of the model

$$
\begin{gathered}
V(d)= \begin{cases}d & \text { if } a_{L}^{2}=1 \\
0 & \text { otherwise }\end{cases} \\
d>0
\end{gathered}
$$

The first proposition states the Subgame Perfect Nash Equilibria for the "low clout" type of MP $(\pi<0)$ and the second proposition states the Subgame Perfect Nash Equilibria for the "high clout" type of MP $(\pi>0)$.

Proposition .1 If the Leader is dealing with a low clout MP, the following strategy profiles form a Subgame Perfect Nash Equilibrium:

1. $(x, 1,0 ; 0,0)$ whenever $b_{M P}<\frac{x}{2}+\frac{r-\pi d}{2 x}$.

2. $(0,1,0 ; 0, x)$ whenever $\frac{x}{2}-\frac{r-\pi d}{2 x} \leq b_{M P} \leq \frac{x}{2}+\frac{r-\pi d}{2 x}$ and $b_{L}<\frac{x}{2}$

3. $(0,1,0 ; x, x)$ and $\left(x, 0,0 ; x, x\right.$ whenever $b_{M P}>\frac{x}{2}+\frac{r-\pi d}{2 x}$.

4. $(x, 0,1 ; 0, x)$ whenever $\frac{x}{2}-\frac{r-\pi d}{2 x} \leq b_{M P} \leq \frac{x}{2}+\frac{r-\pi d}{2 x}$ and $b_{L} \geq \frac{x}{2}$

Proposition .2 If the Leader is dealing with a high clout MP, the following strategy profiles form a Subgame Perfect Nash Equilibrium:

1. $(0,0,0 ; 0,0)$ whenever $b_{M P}<\frac{x}{2}+\frac{r}{2 x}$ and $b_{L}<\frac{x}{2}$

2. $(x, 0,0 ; 0,0)$ whenever $b_{M P}<\frac{x}{2}+\frac{r}{2 x}$ and $b_{L} \geq \frac{x}{2}$ 
3. $(0,0,0 ; 0, x)$ whenever $\frac{x}{2}-\frac{r}{2 x} \leq b_{M P} \leq \frac{x}{2}+\frac{r}{2 x}$ and $b_{L}<\frac{x}{2}$

4. $(x, 0,0 ; 0, x)$ whenever $\frac{x}{2}-\frac{r}{2 x} \leq b_{M P} \leq \frac{x}{2}+\frac{r}{2 x}$ and $b_{L} \geq \frac{x}{2}$

5. $(0,0,0 ; x, x)$ whenever $b_{M P}>\frac{x}{2}+\frac{r}{2 x}$ and $b_{L}<\frac{x}{2}$

6. $(x, 0,0 ; x, x)$ whenever $b_{M P}>\frac{x}{2}+\frac{r}{2 x}$ and $b_{L} \geq \frac{x}{2}$

Proof The Subgame Perfect Equilibria of the game $\langle N, S, U\rangle$ are calculated by backward induction. Note that in the last period of the game, L chooses to enforce discipline only on low clout MPs, because $-\left(b_{L}-a_{M P}^{1}\right)^{2}-\pi V(d) \geq-\left(b_{L}-a_{M P}^{1}\right)^{2}$ if and only if $\pi<0$. Given this, we analyze the cases in which the MPs follow the leadership's choice separately for the low and high clout MPs. In the case of the low clout MP, $B R_{M P}(x)=x$ iff $-\left(b_{M P}-x\right)^{2}+r \geq$ $-b_{M P}^{2}+\pi d$, which is the case if and only if $b_{M P} \geq \frac{x}{2}+\frac{r-\pi d}{2 x}$, while $B R_{M P}(0)=0$ iff $-b_{M P}^{2}+r>-\left(b_{M P}-x\right)^{2}+\pi d$, which is the case if and only if $b_{M P}<\frac{x}{2}-\frac{r-\pi d}{2 x}$. Thus, the best responses of the low clout MP fall into three regions:

1. If $b_{M P}<\frac{x}{2}-\frac{r-\pi d}{2 x} \Rightarrow B R_{M P}(x)=B R_{M P}(0)=0$

2. If $\frac{x}{2}-\frac{r-\pi d}{2 x} \leq b_{M P} \leq \frac{x}{2}+\frac{r-\pi d}{2 x} \Rightarrow B R_{M P}(x)=x \wedge B R_{M P}(0)=0$

3. $b_{M P}>\frac{x}{2}+\frac{r-\pi d}{2 x} \Rightarrow B R_{M P}(x)=x \wedge B R_{M P}(0)=x$

Given these best responses, we proceed to find the optimal choice of the Leader. In region 1, L will choose $x$ over 0 when dealing with a Low Clout MP if and only if $U_{L}\left(x, B R_{M P}(x)\right) \geq$ $U_{L}\left(0, B R_{M P}(0)\right)$, which is equivalent to $-b_{L}^{2}-\pi \geq-b_{L}^{2}$, simplifying to $\pi \leq 0$, which is always the case, since in the low clout case, $\pi<0$ In region 2 , L will choose $x$ over 0 whenever $\left.U_{L}(x, x)\right) \geq U_{L}(0,0)$, equivalent to $-\left(b_{L}-x\right)^{2} \geq-b_{L}^{2}$ which simplifies to $b_{L} \geq \frac{x}{2}$ In region 3 , L will choose $x$ over 0 when dealing with a low clout MP if and only if $U_{L}(x, x) \geq U_{L}(0, x)$, which is equivalent to $-\left(b_{L}-x\right)^{2} \geq-\left(b_{L}-x\right)^{2}-\pi$, simplifying to $\pi \geq 0$, which is always the case, since in the low clout case, $\pi<0$.

In the case of the high clout MP, $B R_{M P}(x)=x$ iff $-\left(b_{M P}-x\right)^{2}+r \geq-b_{M P}^{2}$, which is the case if and only if $b_{M P} \geq \frac{x}{2}-r 2 x$, while $B R_{M P}(0)=0$ iff $-b_{M P}^{2}+r>-\left(b_{M P}-x\right)^{2}$, which is the case if and only if $b_{M P}<\frac{x}{2}-r 2 x$. Thus, the best responses of the high clout MP fall into three regions:

1. If $b_{M P}<\frac{x}{2}-\frac{r}{2 x} \Rightarrow B R_{M P}(x)=B R_{M P}(0)=0$

2. If $\frac{x}{2}-\frac{r}{2 x} \leq b_{M P} \leq \frac{x}{2}+\frac{r}{2 x} \Rightarrow B R_{M P}(x)=x \wedge B R M P(0)=0$

3. $b_{M P}>\frac{x}{2}+\frac{r}{2 x} \Rightarrow B R_{M P}(x)=x \wedge B R_{M P}(0)=x$

Given these best responses, in analogy to the high clout case, we proceed to find the optimal choice of the Leader. In region 1 , L will choose $x$ over 0 when dealing with a high clout $\mathrm{MP}$ if and only if $U_{L}\left(x, B R_{M P}(x)\right) \geq U_{L}\left(0, B R_{M P}(0)\right)$, which is equivalent to $-b_{L}^{2}$ geq $-b_{L}^{2}$, which means both actions are optimal. In region $2, \mathrm{~L}$ will choose $x$ over 0 whenever $\left.U_{L}(x, x)\right) \geq U_{L}(0,0)$, equivalent to $-\left(b_{L}-x\right)^{2} \geq-b_{L}^{2}$ which simplifies to $b_{L} \geq \frac{x}{2}$ In region 3 , L will choose $x$ over 0 when dealing with a low clout MP if and only if $U_{L}(x, x) \geq$ $U_{L}(0, x)$, which is equivalent to $-\left(b_{L}-x\right)^{2} \geq-\left(b_{L}-x\right)^{2}$, which means both actions are optimal. 